\title{
(Re)présenter les savoirs
}

\section{Christophe Didier}

\section{(2) OpenEdition}

Journals

Édition électronique

URL : https://journals.openedition.org/rbnu/2670

DOI : $10.4000 /$ rbnu. 2670

ISSN : 2679-6104

\section{Éditeur}

Bibliothèque nationale et universitaire de Strasbourg

\section{Édition imprimée}

Date de publication : 1 novembre 2012

Pagination : 7

ISSN : 2109-2761

\section{Référence électronique}

Christophe Didier, «(Re)présenter les savoirs », La Revue de la BNU [En ligne], 6 | 2012, mis en ligne le 01 novembre 2012, consulté le 08 août 2021. URL : http://journals.openedition.org/rbnu/2670 ; DOI https://doi.org/10.4000/rbnu.2670

\section{(c) (i) (3)(2)}

La Revue de la BNU est mise à disposition selon les termes de la Licence Creative Commons Attribution - Pas d'Utilisation Commerciale - Partage dans les Mêmes Conditions 4.0 International. 


\section{LE DOSSIER}

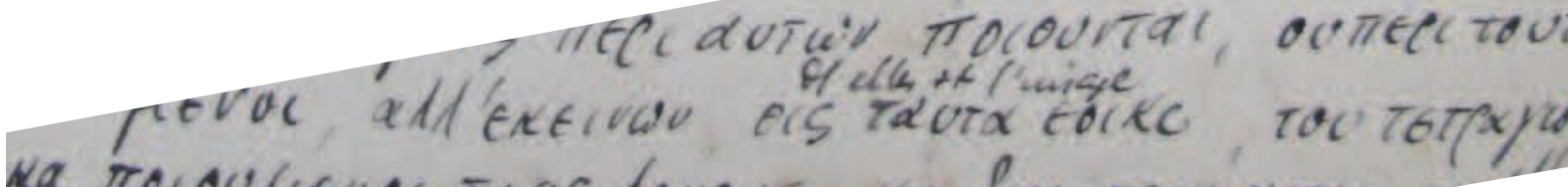

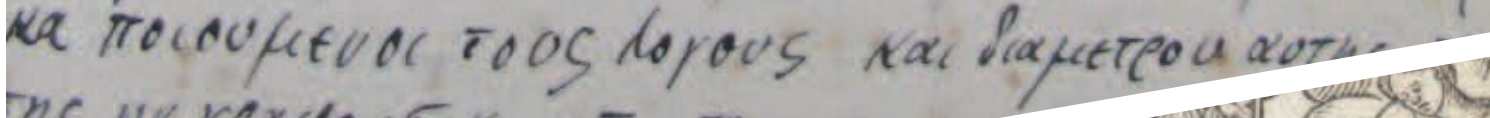

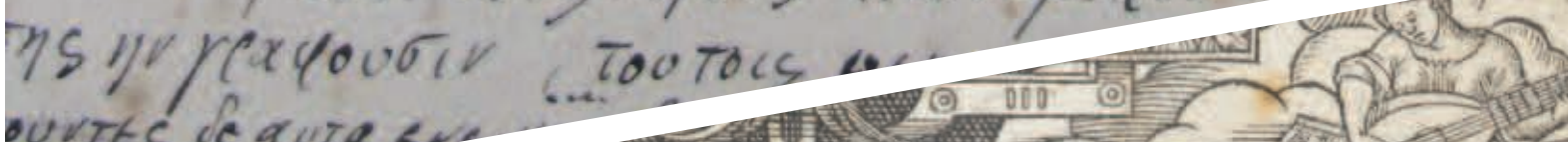

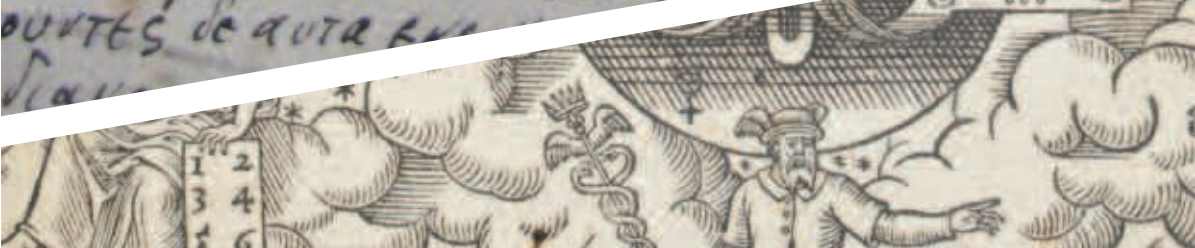

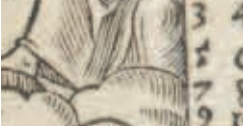
Arithmectica $) * * 2 *$

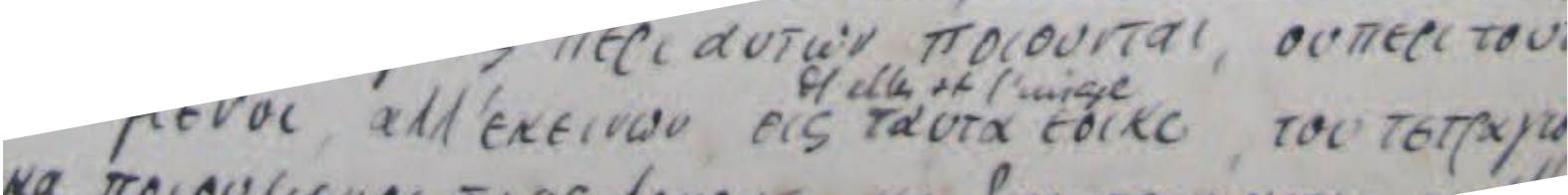
wertivace eiber mog
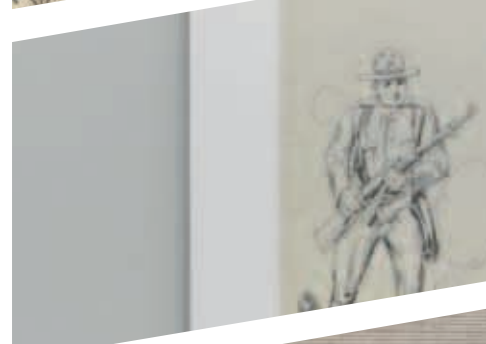

(rim $x$ in
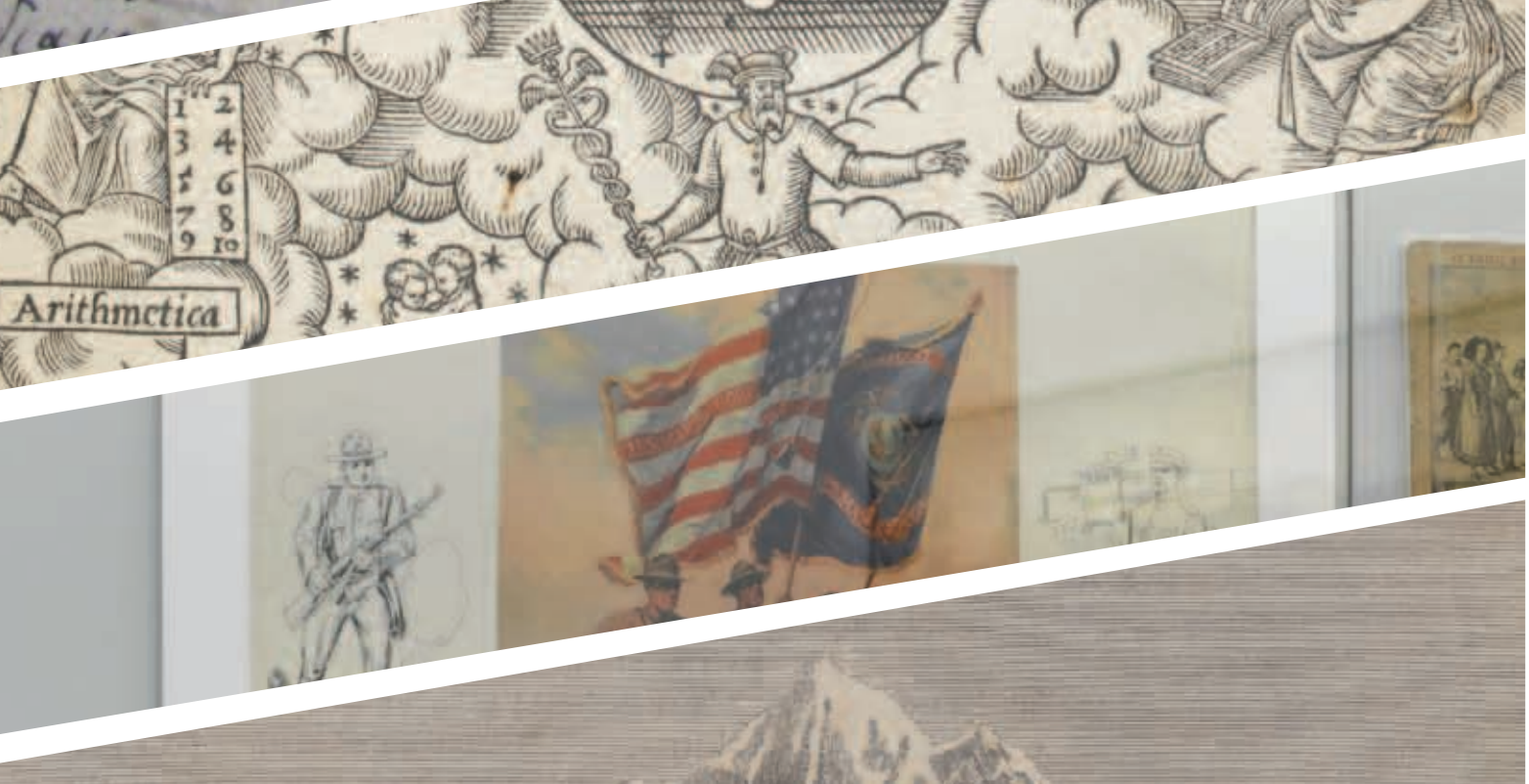


\section{(Re)présenter les savoirs}

Quelles représentations du savoir pour ce début du $21^{\mathrm{e}}$ siècle ? Matériellement, un écran d'ordinateur où toutes les ressources disponibles sont susceptibles de s'afficher en quelques clics, et où le savant, le chercheur d'aujourd'hui inscrivent leurs notes, insèrent leurs commentaires, écrivent enfin. Intellectuellement aussi, l'ordinateur s'impose - ou plutôt les possibilités qu'il offre, via le réseau Internet, de diffusion et d'affichage ; passant largement outre les réseaux traditionnels de validation des savoirs (qui subsistent cependant), l'ère du numérique semble d'une part préparer ce qu'on a pu appeler le " sacre de l'amateur " (pour reprendre l'expression de Patrice Flichy), où tout un chacun peut afficher $s a$ représentation du savoir l'exemple par excellence étant constitué par Wikipédia, aboutissement ultime de construction des savoirs pour les uns, triomphe d'une pensée molle et d'un " easy thinking " pour les autres. D'un autre côté, peut-on envisager aujourd'hui de présenter une science (au sens premier de ce mot) autrement que par les voies multiformes du papier et du numérique, l'un renvoyant sans cesse à l'autre, à l'image même de cette revue ?

Représenter pour mieux présenter est par ailleurs l'un des enjeux majeurs de la science en acte, lorsqu'il s'agit d'imposer un savoir ; en ce sens, il existe bien un théâtre de la science dont la mise en scène est partie intégrante du processus de démonstration. Le frontispice du livre de la Renaissance, pensé comme un décor savant, le musée scientifique du $20^{\mathrm{e}}$ siècle, l'exposition, l'image de synthèse aujourd'hui si familière participent de la même médiation par laquelle le savoir se met en scène,

et qui représente, aujourd'hui comme jamais, un enjeu de taille dans l'efficacité de la transmission. En va-t-il d'ailleurs autrement dans l'aménagement des bibliothèques, dont la " mise en scène ", si l'on peut s'exprimer ainsi, procède souvent d'une présentation maximale, où les livres en accès libre, les postes informatiques, les équipements culturels (auditoriums, salles d'expositions) trahissent les ambitions considérables de média(tisa)tion. " Tous les savoirs du monde... "

Alors, ces savoirs, qu'est-ce qui les (re)présente le mieux ? Le foisonnement désordonné d'Internet, une " bibliothèque-learning center " d'aujourd'hui, les notes manuscrites d'un savant au cours de ses lectures? On se doute bien que la réponse est impossible, ou qu'il faudrait à tout le moins des pages entières pour la tenter (le dossier qui suit ?). En attendant, pourquoi ne pas admettre qu'au fond cette réponse importe peu, et que la variété des représentations est aussi ce qui permet d'ancrer sur les savoirs les propensions à la rêverie, à la méditation, à l'imaginaire, que ceux-ci se manifestent par la visualisation d'une rue sur Google Street View, par la contemplation des architectures fantastiques d'un recueil de gravures ou par la visite d'une exposition.

\section{Christophe Didier}

